\title{
Hearing Profile in Thyroid Dysfunction
}

\author{
Mostafa Adly Tantawy*1 MB. BCH, Ali Abdel-Daiem Ali ${ }^{2}$ MD, Ahmed Mohamed Ahmed Mahmoud ${ }^{2}$ MD, \\ Mohammed Salah Hussein ${ }^{3}$ MD
}

\author{
*Corresponding Author \\ Mostafa Adly Tantawy \\ dr.adlymostafa@gmail.com
}

Received for publication July 7, 2020; Accepted September 3, 2020; Published online September 3, 2020

\section{Copyright 2020 The Authors published by Al-Azhar University, Faculty of Medicine, Cairo, Egypt. All rights reserved. This an open-access article distributed under the legal terms, where it is permissible to download and share the work provided it is properly cited. The work cannot be changed in any way or used commercially. \\ doi: 10.21608/aimj.2020.33445.1260 \\ ${ }^{1}$ Department of Audiology, Al-Ahrar Educational Hospital, Zagazig, Egypt. \\ ${ }^{2}$ Department of Audiology, Faculty of Medicine, Al-Azhar University, Cairo, Egypt. \\ ${ }^{3}$ Department of Internal Medicine, Faculty of Medicine, Al-Azhar University, Cairo, Egypt.}

\begin{abstract}
Background: The etiology of hearing loss may be of endocrine or metabolic abnormalities with varying degrees.

Objective: Define how changes in thyroid hormone levels could affect the hearing system and characterize the audiological or electrophysiological findings of hearing assessment in individuals with acquired thyroid dysfunction.

Material and Methods: Between Dec 2018 - Feb 2020, twenty healthy control subjects, twenty hyperthyroidism, and twenty hypothyroidism patients who are diagnosed in the Department of Endocrinology and Metabolism at Al-Azhar University Hospitals between the ages of 18-50 years old. Pure tone audiometry, speech audiometry, and ABR measurements were performed for each patient.

Results: When audiometric findings of hypothyroid patients were studied, sensorineural hearing loss was detected mainly at high frequencies. When ABR measurements of the hypothyroid group compared to the control group, revealed that wave V. latency was longer in the hypothyroid group.

Conclusion: These changes in ABR waves suggest that there are retro-cochlear problems in hypothyroid patients.
\end{abstract}

Keywords: Hypothyroid; Hyperthyroid; Audiometry; ABR; Hearing loss

Disclosure: The authors have no financial interest to declare in relation to the content of this article. The Article

Processing Charge was paid for by the authors.

Authorship: All authors have a substantial contribution to the article

\section{INTRODUCTION}

Multiple factors can affect hearing loss like genetic or environmental. Also several endocrine and metabolic abnormalities may lead to different degrees of hearing loss. The neurophysiology of hearing and anatomical structure of the auditory pathway is affected by changes in the hormonal and metabolic systems. ${ }^{1}$

Before the very onset of hearing thyroid hormones act through thyroid hormone $\beta$ receptors to influence hearing by initiating myelinogenesis of the vestibulocochlear nerve (VIII cranial nerve). ${ }^{2}$ In addition to the expression of prestin (cochlear protein), that regulates functions of outer hair cells, has been proved to reduce in thyroid hormone deficiency. ${ }^{3}$
Hypothyroidism is considered a cause of the diminution of hearing. About twenty-five percent of patients with acquired hypothyroidism complain hearing loss, with partial reversibility after thyroid hormone replacement treatment. ${ }^{4}$

\section{PATIENTS AND METHODS}

Subjects:

A control group of 20 healthy volunteers (Group A) with normal thyroid function test were hearing-assessed in the Department of Audiology and Vestibular Medicine at Al-Azhar University Hospitals, the group included 10 males and 10 females with a mean age of 32.5 years and hearing threshold better than 25 dBHTL concerning frequency range 250-8000 $\mathrm{Hz}$. 
The hyperthyroid group (Group B) comprised 20 patients with acquired hyperthyroidism of mean age $35.4 ; 13$ were males and 7 were females. While the hypothyroid group (Group C) comprised 20 patients with acquired hypothyroidism of mean age 37.95 ; 10 were males and 10 were females; both groups were diagnosed in the Department of Endocrinology and Metabolism at Al-Azhar University Hospitals. Any other causes of hearing loss were excluded as so any neurological disorders or systemic diseases that may interrupt with electrophysiological measures.

Based on findings of a previous paper Thornton and Jarvis, ${ }^{5}$ regarding pure tone thresholds of the average $2-4 \mathrm{kHz}$, the difference between hypothyroid $(24.3 \pm 11)$ and control $(11.7 \pm 5)$ was significant $(\mathrm{p}<0.005)$; so based on that with the power of $80.0 \%$ and confidence level of $95 \%$ the minimum sample size calculated to be fifteen in each group and with the non-responder rate we took twenty.

Equipments:

Two-channel Audiometer Inter-acoustics model AC40 with headphones TDH 39 and bone vibrator B71, Acoustic Immittancemeter Inter-acoustics model AZ26 with $220 \mathrm{~Hz}$ probe tone and Evoked potential system (ABR) Smart Intelligent.

Procedures:

All subjects were submitted to carefully taken full history, thyroid function test, otological examination, and hearing assessment including immittancemetry with ipsilateral acoustic reflexes, pure tone audiometry (PTA), speech audiometry, and auditory brain stem response (ABR) at a low repetition rate 21.1 clicks/sec and high repetition rate 71.1 clicks/sec.

\section{Statistical Analysis:}

Data obtained through history taking, clinical assessment, and laboratory tests were analyzed using Microsoft Excel software. The data were then imported into Statistical Package for the Social Sciences (SPSS version 20.0) software for analysis. Based on the form of data; qualitative data expressed as number and percentage while quantitative data for the continuous group is represented by mean $\pm \mathrm{SD}$. The following measures were used to assess significant differences in the qualitative variable by the Chi-square test $\left(\mathrm{X}^{2}\right)$. Differences between quantitative independent multiple groups by ANOVA.

Ethical considerations: The study was approved by the ethical committee of Al-Azhar University, Egypt. Verbal and written consent was taken from all participants and they were free to leave the study at any time.

\section{RESULTS}

Table (1) shows age and gender distribution among studied groups. Mean age was $32.5 \pm 8.55,35.4 \pm 9.17$, and $37.95 \pm 8.1$ years old among control, hyperthyroid and hypothyroid groups respectively with no significant difference among studied groups $\mathrm{P}>0.05$.

Pure tone audiogram thresholds among three studied groups are shown in Table (2) showing that there is no significant difference between the three groups as regard frequency range $250 \mathrm{~Hz}-2000 \mathrm{~Hz}$. While the hypothyroid group was significantly higher than the other two groups regarding 4000 $\mathrm{Hz}$ and $8000 \mathrm{~Hz}$ on both right and left ears.

Table (3) shows the distribution of low and high-frequency audiogram thresholds among studied groups showing that the hypothyroid group was significantly higher than the other two groups regarding high-frequency thresholds.

Distribution of right and left word discrimination scores among studied groups are shown in Table (4) showing no significant difference between the three studied groups.

Acoustic reflexes of the studied groups are distributed and tabulated in Table (5) showing that the hypothyroid group was significantly higher than the other two groups regarding 1000 $\mathrm{Hz}$ and $2000 \mathrm{~Hz}$ on the right ear and $500 \mathrm{~Hz}, 1000 \mathrm{~Hz}$, and 2000 $\mathrm{Hz}$ on the left ear.

Low and High repetition rate ABR among studied groups was compared in Table (6) showing that ABR results as regarding wave $\mathrm{V}$ latencies were significantly higher among the hypothyroid group on both right and left ears.

\begin{tabular}{|c|c|c|c|c|c|c|c|}
\hline & & & Group A & Group B & Group C & $\mathrm{F}$ & $\mathrm{P}$ \\
\hline \multicolumn{3}{|c|}{ Mean age in years } & $32.5 \pm 8.55$ & $35.4 \pm 9.17$ & $37.95 \pm 8.1$ & 1.987 & 0.147 \\
\hline \multirow[t]{4}{*}{ Gender } & \multirow[t]{2}{*}{ Female } & $\mathrm{N}$ & 10 & 7 & 10 & \multirow{4}{*}{1.21} & \\
\hline & & $\%$ & $50.0 \%$ & $35.0 \%$ & $50.0 \%$ & & \\
\hline & \multirow[t]{2}{*}{ Male } & $\mathrm{N}$ & 10 & 13 & 10 & & 0.54 \\
\hline & & $\%$ & $50.0 \%$ & $65.0 \%$ & $50.0 \%$ & & \\
\hline \multirow{2}{*}{\multicolumn{2}{|c|}{ Total }} & $\mathrm{N}$ & 20 & 20 & 20 & & \\
\hline & & $\%$ & $100.0 \%$ & $100.0 \%$ & $100.0 \%$ & & \\
\hline
\end{tabular}

Table (1): Age and gender distribution among studied groups

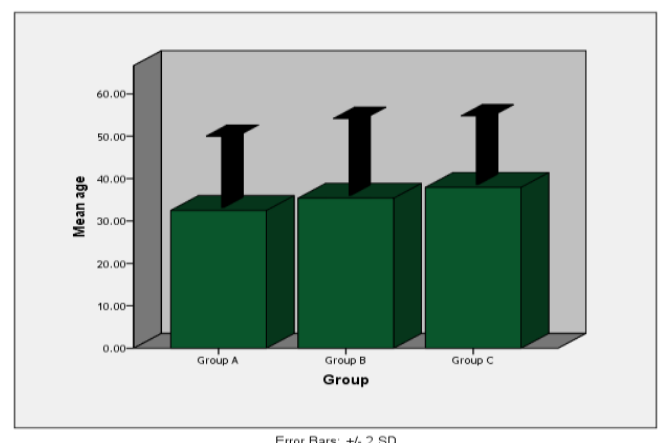

Figure (1): Mean age distribution among the three studied groups showing no significant difference. 


\begin{tabular}{|c|c|c|c|c|c|c|}
\hline & & \multicolumn{3}{|c|}{ Thresholds in dBHL } & \multirow[b]{2}{*}{$\mathbf{F}$} & \multirow[b]{2}{*}{$\mathbf{P}$} \\
\hline \multicolumn{2}{|c|}{ Frequency in $\mathrm{Hz}$} & Group A & Group B & Group C & & \\
\hline \multirow{6}{*}{ 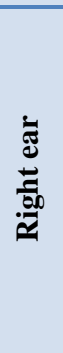 } & 250 & $11.0 \pm 3.47$ & $10.5 \pm 4.55$ & $12.0 \pm 4.1$ & 0.704 & 0.499 \\
\hline & 500 & $12.75 \pm 3.43$ & $13.5 \pm 4.1$ & $13.25 \pm 3.35$ & 0.186 & 0.831 \\
\hline & $1 \mathrm{~K}$ & $15.0 \pm 3.62$ & $15.5 \pm 3.94$ & $17.0 \pm 3.76$ & 1.515 & 0.228 \\
\hline & $2 \mathrm{~K}$ & $17.0 \pm 4.1$ & $18.0 \pm 4.41$ & $19.5 \pm 3.59$ & 1.930 & 0.154 \\
\hline & $4 \mathrm{~K}$ & $19.75 \pm 4.43$ & $20.75 \pm 4.06$ & $24.5 \pm 4.55^{*}$ & 6.604 & $0.003 *$ \\
\hline & $8 \mathrm{~K}$ & $21.5 \pm 4.61$ & $22.25 \pm 3.43$ & $25.5 \pm 6.04^{*}$ & 3.893 & $0.026^{*}$ \\
\hline \multirow{6}{*}{ 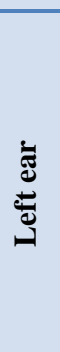 } & 250 & $10.5 \pm 3.94$ & $10.5 \pm 4.55$ & $11.75 \pm 4.06$ & 0.592 & 0.557 \\
\hline & 500 & $11.5 \pm 2.85$ & $13.25 \pm 4.66$ & $13.25 \pm 3.35$ & 1.487 & 0.235 \\
\hline & $1 \mathrm{~K}$ & $14.75 \pm 3.02$ & $15.25 \pm 3.79$ & $17.25 \pm 3.43$ & 2.972 & 0.059 \\
\hline & $2 \mathrm{~K}$ & $17.7 \pm 3.4$ & $18.25 \pm 4.66$ & $19.5 \pm 2.76$ & 3.105 & 0.052 \\
\hline & $4 \mathrm{~K}$ & $19.75 \pm 3.79$ & $21.5 \pm 4.0$ & $24.25 \pm 3.72 *$ & 6.963 & $0.002 *$ \\
\hline & $8 \mathrm{~K}$ & $21.75 \pm 4.66$ & $21.77 \pm 3.72$ & $27.0 \pm 7.32 *$ & 6.170 & $0.004^{*}$ \\
\hline
\end{tabular}

Table (2): right and left pure tone audiogram thresholds distribution among the three studied groups.

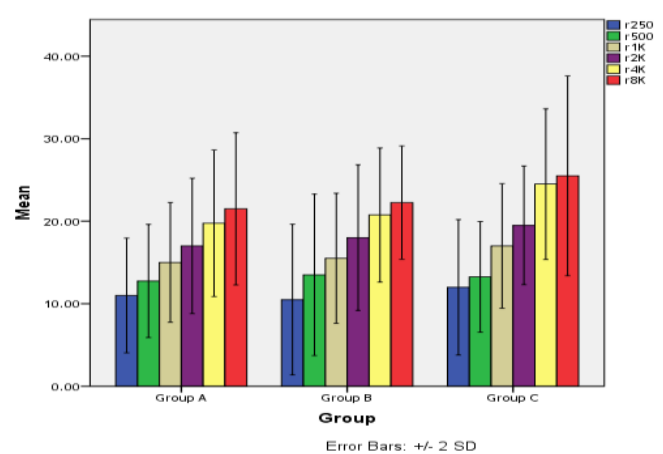

Figure (2a): Right ear pure tone thresholds of the three studied groups showing that Group $\mathrm{C}$ was significantly higher than the other two groups regarding $4 \mathrm{kHz}$ and $8 \mathrm{kHz}$.

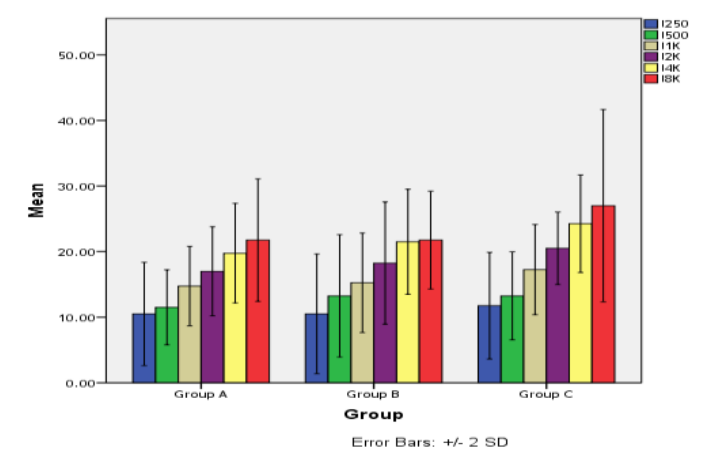

Figure (2b): left ear pure tone thresholds of the three studied groups showing that Group $\mathrm{C}$ was significantly higher than the other two groups regarding $4 \mathrm{kHz}$ and $8 \mathrm{kHz}$

\begin{tabular}{|c|c|c|c|c|c|c|}
\hline & & \multicolumn{3}{|c|}{ Mean thresholds in dBHL } & \multirow[b]{2}{*}{$\mathbf{F}$} & \multirow{2}{*}{$\mathbf{P}$} \\
\hline & & Group A & Group B & Group C & & \\
\hline \multirow[t]{2}{*}{ Right } & Low & $12.91 \pm 3.19$ & $13.16 \pm 4.11$ & $14.08 \pm 3.35$ & 0.590 & 0.558 \\
\hline & High & $19.41 \pm 3.94$ & $20.33 \pm 3.44$ & $23.16 \pm 3.7 *$ & 5.571 & $0.006^{*}$ \\
\hline \multirow[t]{2}{*}{ Left } & Low & $12.25 \pm 2.87$ & $13.0 \pm 3.95$ & $14.08 \pm 3.12$ & 1.511 & 0.229 \\
\hline & High & $19.5 \pm 3.63$ & $20.5 \pm 3.5$ & $23.91 \pm 3.75 *$ & 8.123 & $0.001 * *$ \\
\hline
\end{tabular}

Table (3): Low and high-frequency pure tone thresholds of both right and left ears among studied groups.

\begin{tabular}{|c|c|c|c|c|c|}
\hline & \multicolumn{3}{|c|}{ Word discrimination score } & \multirow{2}{*}{ F } & P \\
\cline { 2 - 4 } & Group A & Group B & Group C & 2.452 & 0.071 \\
\hline Right Ear & $0.97 \pm 0.03$ & $0.98 \pm 0.04$ & $0.97 \pm 0.021$ & 2.0434 & 0.064 \\
\hline Left Ear & $0.97 \pm 0.03$ & $0.98 \pm 0.05$ & $0.97 \pm 0.04$ & 2.534 \\
\hline
\end{tabular}

Table (4): right and left distribution of word discrimination score among studied groups 


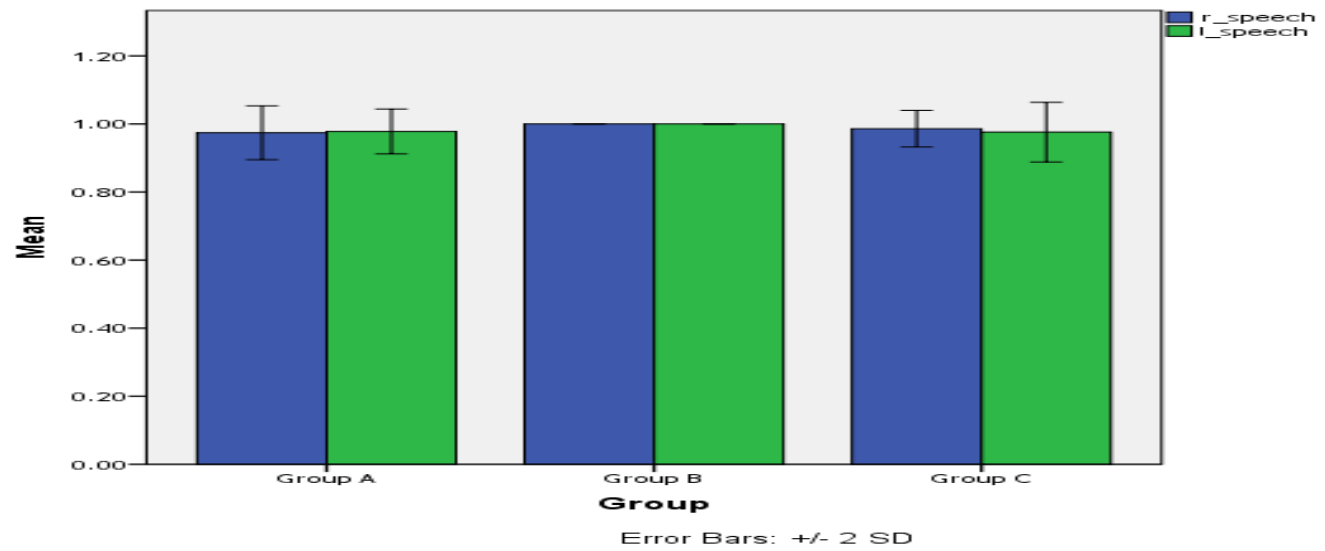

Figure (3): Distribution of right and left word discrimination score among the three groups showing no significant difference.

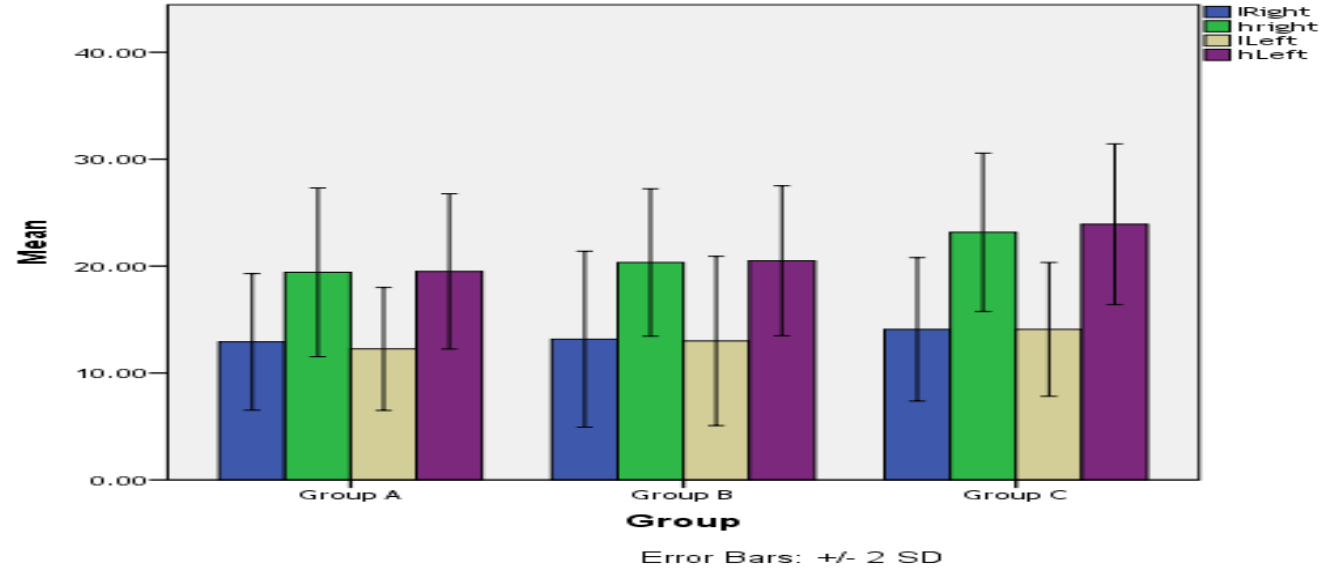

Figure (4): Low and high-frequency pure tone thresholds on both ears among the three studied groups showing that Group C was significantly higher than the other two groups regarding high frequency.

\begin{tabular}{|c|c|c|c|c|c|c|}
\hline \multirow{2}{*}{\multicolumn{2}{|c|}{ Frequency in $\mathrm{Hz}$}} & \multicolumn{3}{|c|}{ Acoustic reflexes thresholds in dBHL } & \multirow[b]{2}{*}{$\mathbf{F}$} & \multirow[b]{2}{*}{$\mathbf{P}$} \\
\hline & & Group A & Group B & Group C & & \\
\hline \multirow{4}{*}{ है } & 500 & $86.5 \pm 4.89$ & $86.25 \pm 5.09$ & $88.12 \pm 3.72$ & 0.453 & 0.639 \\
\hline & $1 \mathrm{~K}$ & $89.0 \pm 4.75$ & $88.5 \pm 4.61$ & $96.5 \pm 6.25^{*}$ & 9.558 & $0.00 * *$ \\
\hline & $2 \mathrm{~K}$ & $93.25 \pm 4.37$ & $91.75 \pm 3.35$ & $101.0 \pm 6.58 *$ & 14.586 & $0.00 * *$ \\
\hline & $4 \mathrm{~K}$ & $97.35 \pm 3.99$ & $96.0 \pm 3.07$ & $96.11 \pm 3.33$ & 0.766 & 0.471 \\
\hline \multirow{4}{*}{ ్ㅣㄹ } & 500 & $86.75 \pm 4.06$ & $86.25 \pm 3.93$ & $93.0 \pm 10.36$ & 3.851 & $0.029 *$ \\
\hline & $1 \mathrm{~K}$ & $90.5 \pm 4.55$ & $89.0 \pm 4.75$ & $97.85 \pm 8.09$ & 7.480 & $0.002 *$ \\
\hline & $2 \mathrm{~K}$ & $94.25 \pm 3.35$ & $92.25 \pm 3.02$ & $97.5 \pm 4.18$ & 6.076 & $0.005 *$ \\
\hline & $4 \mathrm{~K}$ & $97.05 \pm 4.35$ & $95.0 \pm 3.62$ & $96.25 \pm 2.5$ & 1.306 & 0.283 \\
\hline
\end{tabular}

Table (5): right and left ipsilateral reflexes thresholds distribution among the studied groups.

\begin{tabular}{|c|c|c|c|c|c|c|}
\hline & & \multicolumn{3}{|c|}{ Wave V Latencies in millisecond } & \multirow[b]{2}{*}{$\mathbf{F}$} & \multirow[b]{2}{*}{$\mathbf{P}$} \\
\hline \multicolumn{2}{|c|}{ Repetition rate } & Group A & Group B & Group C & & \\
\hline \multirow{2}{*}{ 的 } & Low & $5.45 \pm 0.16$ & $5.41 \pm 0.16$ & $5.89 \pm 0.11 *$ & 29.437 & $0.00 * *$ \\
\hline & High & $6.21 \pm 0.13$ & $6.17 \pm 0.39$ & $6.89 \pm 0.26^{*}$ & 48.703 & $0.00 * *$ \\
\hline \multirow{2}{*}{ 产 } & Low & $5.34 \pm 0.33$ & $5.43 \pm 0.17$ & $6.08 \pm 0.08 *$ & 32.789 & $0.00 * *$ \\
\hline & High & $6.33 \pm 0.17$ & $6.22 \pm 0.34$ & $7.06 \pm 0.18^{*}$ & 88.753 & $0.00 * *$ \\
\hline
\end{tabular}

Table (6): low and high repetition rate ABR wave V latencies in msec. of both right and left ears among studied groups. Group $\mathrm{C}$ was significantly higher than the other two groups regarding low and high repetition rates. 
Audiology

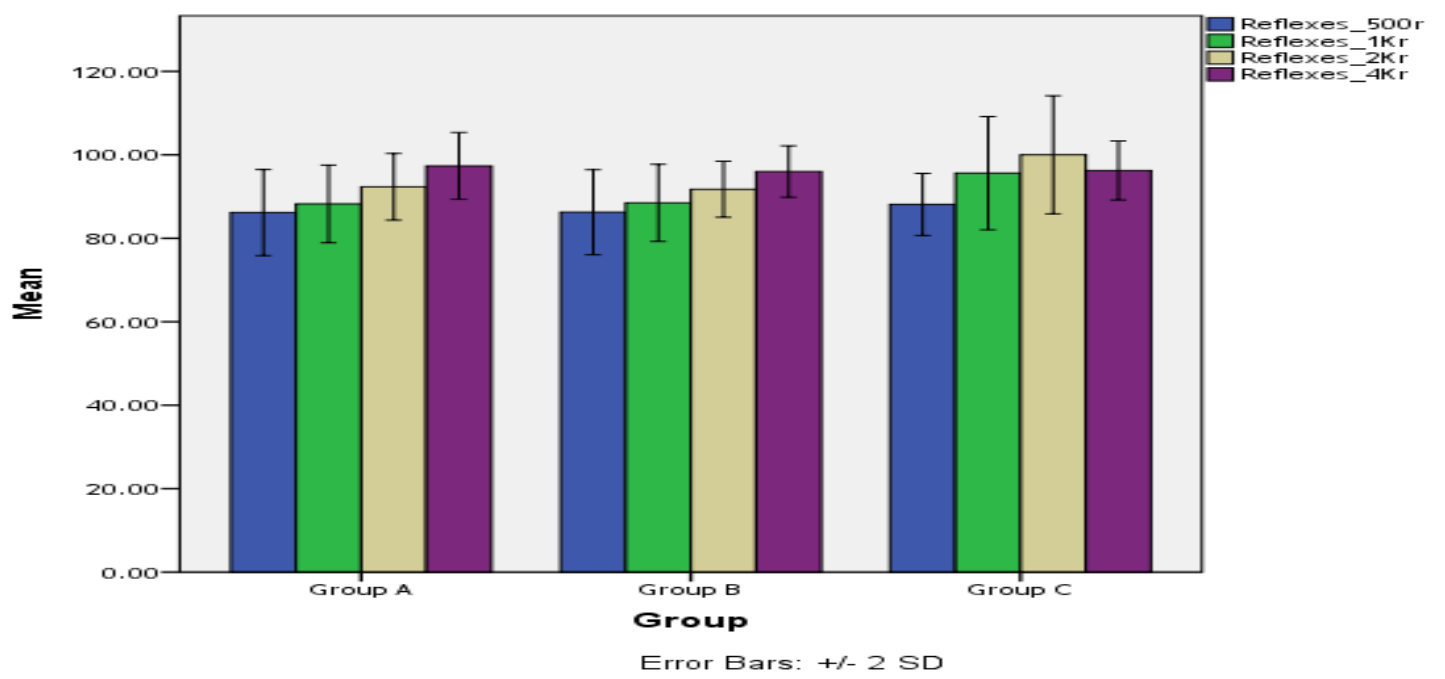

Figure (5a): Right ear ipsilateral reflexes distribution among studied groups showing that Group C was significantly higher than the other two groups regarding $1 \mathrm{kHz}$ and $2 \mathrm{kHz}$.

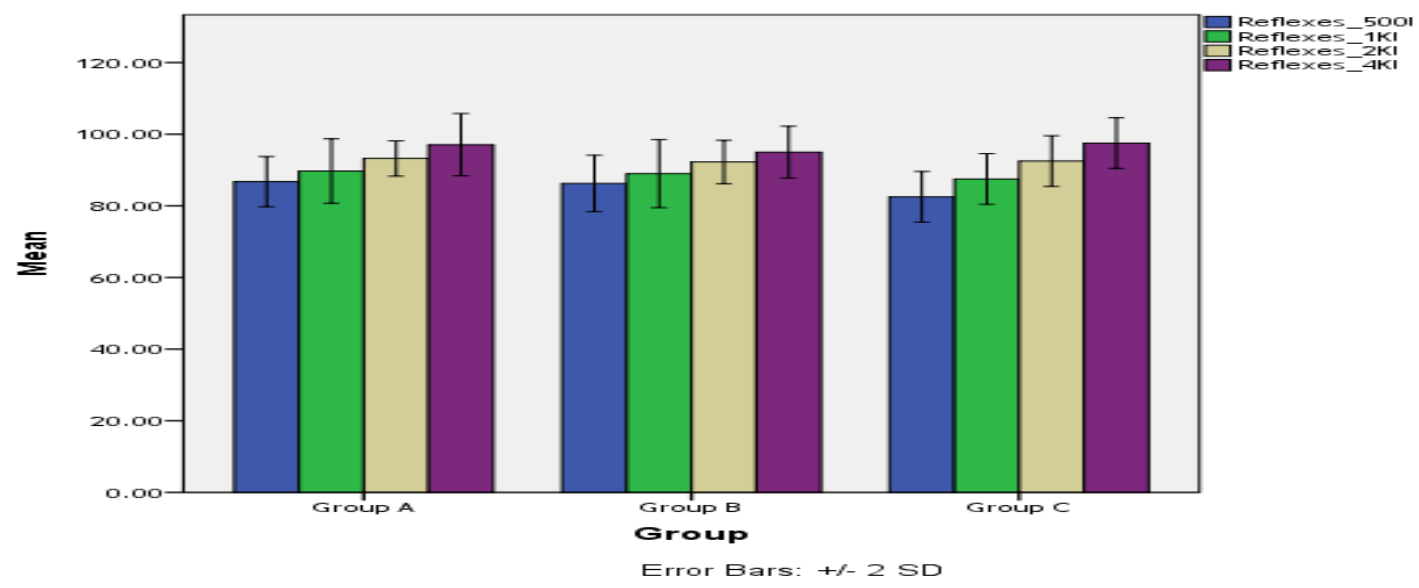

Figure (5b): Left ear ipsilateral reflexes distribution among studied groups showing that Group C was significantly higher than the other two groups regarding $500 \mathrm{~Hz}, 1 \mathrm{kHz}$, and $2 \mathrm{kHz}$.

\section{DISCUSSION}

Hypothyroidism is defined as a decrease in serum concentration of thyroid hormones that leads to elevated serum TSH concentration and hyperthyroidism is described by a low serum level of TSH and increased thyroid hormones serum concentration. The normal range of FT3, FT4 and TSH serum levels is $0.2-0.5 \mathrm{ng} / \mathrm{dL}, 0.7-2.5 \mathrm{ng} / \mathrm{dL}$ and $0.4-4.2 \mathrm{mU} / \mathrm{L}$ respectively. ${ }^{6}$

In the current study, the assessment of patients with acquired hypothyroidism and hyperthyroidism was studied in detail when compared to the control group to define the degree of hearing loss. Results showed that there was no significant difference between the three groups regarding frequency range $250 \mathrm{~Hz}-2000 \mathrm{~Hz}$ in both ears, but when high frequencies were recorded; subjects of group $\mathrm{C}$ were significantly higher than the other two groups at $4000 \mathrm{HZ}$ and $8000 \mathrm{HZ}$. This is an agreement with Thornton and Jarvis, ${ }^{5}$ compared between hypothyroid and hyperthyroid patients;

found that the average threshold was above twenty-five $\mathrm{dB}$ in hypothyroid patients results while no significant difference between control and hyperthyroid patients results. They supposed that the significant alteration may be due to variation in the hormonal level which leads to changes in the metabolism and physiological criteria within cells in the retro-cochlear auditory pathway.

Also Karali and $\mathrm{Guclu}^{7}$ Studied twenty-five hypothyroid patients and reported that comparison of the airway threshold values obtained by audiometry revealed that the hypothyroid group was found higher at high frequencies when compared to the control group. However there was no significant difference at $500 \mathrm{~Hz}-4000 \mathrm{~Hz}$, they found a statistically significant difference at $8000 \mathrm{~Hz}$. In a study conducted on 30 hypothyroid 
patients, Santos et al. ${ }^{8}$ detected a moderate sensorineural hearing loss in twenty-two of the sixty ears and reported that there were bilateral hearing losses.

On the other hand, Berker et al. ${ }^{9}$ examined twenty-two cases of Grave's disease and documented sensorineural hearing loss particularly at high frequencies in most cases.

Acoustic reflexes in the 3 groups; control, hyperthyroid and hypothyroid patients were measured and results showed a highly significant difference $(\mathrm{p}<0.05)$ in ipsilateral acoustic reflexes among group $\mathrm{C}$ when compared to group $\mathrm{A}$ and group $\mathrm{B}$ specifically at $1000 \mathrm{HZ}$ and $2000 \mathrm{~Hz}$ on the right ear and at 500 $\mathrm{Hz}, 1000 \mathrm{~Hz}$ and $2000 \mathrm{~Hz}$ on the left ear. Results match up with Bruschini et al. ${ }^{10}$ who stated elevated acoustic reflexes in patients with hypothyroidism when compared with the normal group. On the other hand, also stated elevated acoustic reflexes in hyperthyroid patients and mentioned that acoustic reflexes of both groups were elevated when compared with the control group.

There was no significant variation between the 3 studied groups when word discrimination score was measured, that might be due to the fact of discrimination score is more strongly correlated with the average of frequencies $500 \mathrm{~Hz}, 1000 \mathrm{~Hz}, 20000 \mathrm{~Hz}$, and $4000 \mathrm{~Hz} .{ }^{11}$ Regarding this average of frequencies; discrimination does not depend only on $4000 \mathrm{~Hz}$ which was earlier proved to be affected by low thyroid hormones in group $\mathrm{C}$ of hypothyroid patients.

It is known that electrophysiological changes are seen in thyroid diseases. Calcium absorption decreases in hypothyroidism. Calcium is effective on synaptic transmission in the nervous system, so that hearing loss due to brain stem pathologies may occur in hypothyroidism. ${ }^{5}$

In the current study regarding the ABR test with a low repetition rate at a rate of 21.1 clicks/sec or high repetition rate at a rate of 71.1 clicks/sec when results of hyperthyroid patients are compared to the control group, no statistically significant difference was found about wave $\mathrm{V}$ absolute latency. Although a statistically significant prolongation in absolute wave $\mathrm{V}$ latency could be detected in patients with hypothyroidism.

Those findings were following Santos et al. ${ }^{8}$ who believed there may be some sluggish peripheral conduction in hypothyroidism. Also, Figueiredo et al. ${ }^{12}$ who found a marked increase in absolute wave III and V latencies and interpeak I - III or I - V latencies in hypothyroid patients.

In addition to Karali and Guclu, ${ }^{7}$ found that the difference between wave III and V latencies or interpeak I - III latency was statistically significant $(p<0.05)$. Ismail et $a .^{13}$ found a statistically significant delay in absolute wave III and V latencies of $\mathrm{ABR}$ in recently diagnosed patients.

The same as Chanderasekhar et al. ${ }^{14}$ who also have reported an increase in absolute wave latencies in hypothyroid patients may be due to reduced tissue metabolism which may contribute to impaired recruitment of neuronal pools at brainstem wave generators and slow peripheral conduction. Results revealed there was no dramatic difference $(p>0.05)$ between the control group and hyperthyroidism. Kumar et al. ${ }^{15}$ detected significant difference for waves I and III absolute latencies of both ears and wave $\mathrm{V}$ in right.

Khedr et al. ${ }^{16}$ also confirmed elongation of all absolute and interpeak wave latencies affecting both central and peripheral conduction time suggesting that dysfunction in the nervous system is diffuse. Low temperature, decreased myelin development and cerebral metabolism alteration may be the potential exploration for the prolongation of the conduction time. Thornton and Jarvis, ${ }^{5}$ found no key difference ( $\left.p>0.05\right)$ in hyperthyroidism for absolute or inter-peak latencies of waves by evaluating the audiometry and ABR results of twelve hyperthyroid patients as compared to control.
On the other hand, Anjana et al. ${ }^{17}$ have found a significant decrease in latency to wave $\mathrm{V}$. with no critical difference in interpeak latencies for hypothyroid patients, as well as Vanasse et al. ${ }^{18}$ who compared hypothyroid patients to the control group but did not detect a big difference in ABR outcomes. The same as Ozata et al. ${ }^{19}$ who found no abnormalities in ABR of patients with hypothyroidism.

\section{CONCLUSION}

1. Patients with hypothyroidism have poorer pure tone thresholds than age-matched hyperthyroid patients at 4-8 $\mathrm{kHz}$.

2. Vestibulocochlear symptoms like diminution of hearing were more frequent in patients with hypothyroidism.

3. The hearing loss was sensorineural, detected especially at high frequencies in the audiometric findings of hypothyroid patients.

4. Findings that support retro-cochlear hearing loss were found in patients with hypothyroidism, suggesting that ABR results were due to brain stem pathology when compared with the control group.

\section{RECOMMENDATIONS}

1. Furthermore, studies on a large sample size of patients to study with other variables like the duration of disease and the effect of medical intervention.

2. Full awareness plans targeting people complaining diminution of hearing to assess thyroid function.

3. Physicians should be aware of the impact of thyroid dysfunction on hearing to apply the ABR test and detect to what extent the auditory pathway is involved.

4. Widespread public health education programs are needed to increase awareness about the impact of thyroid dysfunction on hearing and post warning labels in health care units.

\section{REFERENCES}

1. Cherian KE, Kapoor N, Mathews SS, and Paul TV. Endocrine Glands and Hearing Manifestations of Various Endocrine and Metabolic Conditions. Indian J. of endocrinology and metabolism. 2017; 21(3): 464-469.

2. Knipper M, Bandtlow C, Gestwa L, Köpschall I, Rohbock K, Wiechers B, Zenner HP, Zimmermann U. Thyroid hormone affects Schwann cell and oligodendrocyte gene expression at the glial transition zone of the VIII ${ }^{\text {th }}$ nerve before cochlea function. Development. 1998; 125(18): 3709- 3718.

3. Weber T, Zimmermann U, Winter H, Mack A, Köpschall I, Rohbock K, Zenner HP, Knipper M. Thyroid hormone is a critical determinant for the regulation of the cochlear motor protein prestin. Proc Natl Acad Sci. 2002; 99(5): 2901-2906.

4. Lichtenberger-Geslin L, Dos Santos S, Hassani Y, Ecosse E, Van Den Abbeele T and Léger J. Factors associated with hearing impairment in patients with congenital hypothyroidism treated since the neonatal period: a national population-based study. The Journal of Clinical Endocrinology \& Metabolism. 2013; 98(9): 3644-3652. 
Audiology

5. Thornton ARD and Jarvis SJ. Auditory brainstem response findings in hypothyroid and hyperthyroid disease. Clinical Neurophysiology. 2008; 119(4): 786-90.

6. Salvatore D, Davies TF, and Schlumberger MJ, Hay ID, and Larsen PR. Thyroid physiology and diagnostic evaluation of patients with thyroid disorders. In: Melmed S, Polonsky KS, Larsen PR, Kronenberg HM, eds. Williams textbook of Endocrinology. $13^{\text {th }}$ ed. Elsevier Saunders. 2016; p: 333-488.

7. Karali E and Guclu E. Evaluation of auditory brainstem responses in hypothyroid and hyperthyroid disease. Düzce University School of Medicine Department of Otolaryngology, Master Thesis. 2009; 13-26.

8. Santos K., Dias N, Mazeto G, Carvalho L, Lapate R, and Martins R. Audiologic evaluation in patients with acquired hypothyroidism. Braz J Otorhinolaryngol. 2010; 76(4): 478-484.

9. Berker D, Karabulut H, Isik S, Tutuncu Y, Ozuguz U et al. Evaluation of hearing loss in patients with Graves“ disease. Endocrine. 2012; 41(1): 116-121.

10. Bruschini P, Sellari FS, Bartalena L, Aghini LF, Mazzeo S et al. Acoustic reflex characteristics in hypo and hyperthyroid patients. Audiology. 1984; 23(1): 38-45.

11. Costa-Guarisco LP. Correlation between hearing loss classifications and speech recognition. Revista CEFAC. 2014; 16(4): 1109-1116.

12. Figueiredo L, Lima M, and Vaisman M. Alternation in an audiometric and otoacoustic emotion in adults' subclinical hypothyroidism. Rev Bras Otorhinolaryngol. 2003; 69:542-547.

13. Ismail N, Hanaa K, Behairy R, and Shoaeb A. Impact of controlling hypothyroidism on auditory dysfunction. $\mathrm{Al}$ Azhar Assiut Medical Journal. 2016; 14:196-202.

14. Chanderashekhar M, Kowsalya V and Vijyalakshmi B. Electrophysiological changes on brainstem auditory evoked potentials in hypothyroid patients. J Pharmacy Research. 2011; 4(8): 2856-2859.

15. Kumar R, Munjal SK, Banumathy N, Bhadada S, and Panda NK. Audiological Profile in Patients with Hypothyroidism and Hyperthyroidism. J Otolaryngol ENT Res. 2017; 6(2): 00156.

16. Khedr EM, El-Toony LF, Tarkhan MN, and Abdella G. Peripheral and Central Nervous System Alterations in Hypothyroidism: Electrophysiological Findings. Neuropsychobiology. 2000; 41(2): 88-94.

17. Anjana $\mathrm{Y}$, Vaney $\mathrm{N}$, Tandon OP, and Madhu SV. Functional status of auditory pathways in hypothyroidism: Evoked potential study. Indian J Physiol Pharmacol. 2006; 50(4): 341-9.

18. Vanasse M, Fischer C, Berthezene F, Roux Y, Volman G, and Mornex R. Normal brainstem auditory evoked potentials in adult hypothyroidism. Laryngoscope. 1989; 99(3): 302-6.

19. Ozata M, Ozkardes A, Corakci A, and Gundogan M. Subclinical hypothyroidism does not lead to alterations either in peripheral nerves or in brainstem auditory evoked potentials (BAEPs). Thyroid. 1995; 5: 201-205. 